\title{
RANCANG BANGUN PEMBANGKIT ONTOLOGI DAN RDF PADA SISTEM E-LEARNING PRIMAGAMAPLUS
}

\author{
Cahya Damarjati ${ }^{1}$, Ahmad Ashari ${ }^{2}$, Sri Suning Kusumawardani ${ }^{1}$ \\ ${ }^{1}$ Jurusan Teknik Elektro dan Teknologi Informasi, Fakultas Teknik, \\ ${ }^{2}$ Jurusan Matematika dan Ilmu Pengetahuan Alam, \\ Fakultas Matematika dan Ilmu Pengetahuan Alam \\ Universitas Gadjah Mada Yogyakarta \\ Jln. Grafika 2, Yogyakarta, 55281 \\ E-mail: cahya.damarjati@live.com
}

\begin{abstract}
PrimagamaPlus is a Primagama e-learning site that has learning contents, education news and articles, online exams and other features. This e-learning site can be used freely by Primagama Students as long as they study in all Primagama branches. PrimagamaPlus implement semantic web technology in its system so that its education resources can be utilized by other web applications. This semantic thecnology is useful for those applications on processing informations. Semantic web is created using RDF/XML syntax. DotNetRDF library is used as semantic web development tool uses. The results of this semantic web development are Ontology Generator, RDF/XML Generator, and RDF/XML Linker. An Ontology Generator generate PrimagamaPlus Content Ontology file, an RDF/XML Generator generate RDF files that correspond with PrimagamaPlus Content changes, and an RDF/XML Linker create HTML link tag that contain RDF file url according to the accessed page by user. Those RDF files can be read by other machine using its semantic web reader.
\end{abstract}

\section{Abstrak}

PrimagamaPlus adalah situs e-learning Primagama yang berisi konten pembelajaran, berita dan artikel edukasi, TryOut Online dan fitur lainnya. Situs e-learning ini dapat digunakan secara gratis oleh Siswa Primagama selama masih belajar les di seluruh cabang Primagama se-Indonesia. PrimagamaPlus menerapkan teknologi web semantik di sistemnya agar resource edukatif yang dimilikinya dapat dimanfaatkan oleh aplikasi-aplikasi lain di Internet, sehingga bermanfaat untuk aplikasi-aplikasi tersebut dalam menyajikan informasi yang mereka berikan. Web semantik yang dibuat menggunakan sintaks RDF/XML. Tool pengembangan web semantik menggunakan library DotNetRDF. Hasil dari pembuatan web semantik ini adalah Pembangkit ontologi, Pembangkit data RDF/XML dan Penampil data RDF/XML. Pembangkit ontologi menghasilkan ontologi konten PrimagamaPlus, Pembangkit Data RDF/XML menghasilkan berkas-berkas RDF yang sesuai dengan konten PrimagamaPlus terkini, dan Penampil RDF membuat tag link HTML berisi url dari berkas RDF sesuai halaman yang diakses pengguna. Berkas-berkas RDF tersebut dapat dikonsumsi oleh mesin lain menggunakan tool pembaca web semantik.

Kata kunci: e-learning, web semantic, resource edukatif, RDF/XML, ontologi

\section{PENDAHULUAN}

Penggunaan teknologi Web Semantik dalam $e$ Learning dapat mempunyai manfaat untuk pengajar dan pelajar. Misalnya, pengajar ingin kelas mana saja yang diambil para pelajarnya, siapa saja yang mengikuti kelasnya, berapa nilai rata-rata pelajar yang mengikuti kelasnya, atau sebagai murid selain kelas ini kelas apa yang sebaiknya mereka ambil selanjutnya, dll. Solusi untuk menjawab pertanyaan - pertanyaan tersebut dapat dilakukan dengan mengeksekusi query SQL (Microsoft Developer Netwrok, n.d.) di database. Dengan menerapkan web semantik pada sistem $e$ Learning adalah langkah untuk membuka dunia dimana sumber daya yang terdistribusi dapat dikonsumsi oleh siapapun. Dengan web semantik, query terhadap sistem tidak hanya dilakukan terhadap satu database, melainkan terhadap informasi-informasi dari sistem edukasi yang terdistribusi, termasuk sumber-sumber daya yang tersedia di web (Tran, n.d.). Teknologi Web semantik yang telah digunakan di dunia Internet sampai saat ini diantaranya adalah RDF, microformats, Open Graph Protocol, dll. RDF adalah web semantik generasi pertama yang dibuat oleh Web konsorsium W3C (Bikakis, et al., 2013). Microformats muncul pada tahun 2005 (Berriman, et al., 2005). Dengan mottonya 
"Designed for humans first and machines second", Microformats mempunyai format yang lebih sederhana dibandingkan RDF dan telah digunakan oleh banyak weblog. OGP yang dibuat oleh pengembang facebook untuk membuat suatu halaman web menjadi sebuah rich object di media sosial. Misalnya, OGP digunakan di Facebook untuk mengubah suatu halaman web agar mempunyai fungsionalitas yang sama terhadap objek-objek yang ada di Facebook (Facebook, 2007). Sekarang, OGP digunakan oleh situs jejaring sosial seperti Facebook, Google Plus, dan Mixi. PrimagamaPlus (PgPlus Team, 2010) adalah situs web yang berisi konten-konten ilmu pengatahuan siswa dari sekolah dasar hingga sekolah menengah atas. PrimagamaPlus mempunyai konten pembelajaran yang berupa modul ebook, artikel smart solution, video pembelajaran, dan konten umum yang dapat diunduh. PrimagamaPlus juga menyediakan mesin tryout sebagai persiapan siswa untuk menghadapi ujian akhir sekolah.

PrimagamaPlus mempunyai banyak konten yang sangat bermanfaat bagi para guru dan siswa dalam proses belajar mengajar. Agar PrimagamaPlus yang berisi beragam informasi dapat ditambang oleh aplikasi atau sistem dari luar maka web semantik perlu diterapkan di situs PrimagamaPlus. Dengan fitur web semantik tersebut, aplikasi lain dapat dengan mudah mengekstrak setiap informasi berharga dari PrimagamaPlus. Oleh karena itu, peneliti mencoba menerapkan pembangkit web semantik RDF dan ontologi konten pembelajaran PrimagamaPlus. Harapannya, setiap data semantik yang dibangkitkan dapat dikonsumsi dengan mudah oleh aplikasi lain yang ingin memanfaatkannya.

\subsection{E-learning}

e-Learning adalah proses pembelajaran mandiri yang difasilitasi dan didukung melalui pemanfaatan Teknologi Informasi dan Komunikasi (Jenkins \& Hanson, 2003). Dari beberapa sistem e-Learning yang dikembangkan hingga saat ini, secara umum dapat dibagi berdasarkan sifat interaktivitasnya menjadi dua kelompok:

\section{a. E-Learning yang bersifat statis}

e-Learning yang bersifat statis. Pengguna sistem ini hanya dapat mengunduh bahan-bahan belajar yang diperlukan. Sedangkan dari sisi administrator, hanya dapat mengunggah file-file materi.

b. E-Learning yang bersifat dinamis Fasilitas yang ada pada sistem ini lebih bervariasi dari apa yang ditawarkan sistem pertama. Pada sistem kedua ini, fasilitas seperti forum diskusi, chating, e-mail, alat bantu evaluasi pembelajaran, manajemen pengguna, serta manajemen materi sudah tersedia

\subsection{Web Semantik}

Web semantik (Berners-Lee, et al., 2001) merupakan paradigma baru dalam membuat, mengelola, dan berbagi informasi melalui pendekatan teknologi Web 2.0 (O'Reilly, 2005). Dalam rangka mencapai tujuan tersebut, layer-layer untuk merepresentasikan struktur web semantik akan dibutuhkan. Gambar layer tersebut terdapat pada Gambar 1. Layer-layer tersebut adalah sebagai berikut (Miller \& Koivunen, 2001):

a. Layer XML, merepresentasikan struktur data

b. Layer RDF, merepresentasikan arti data

c. Layer Ontologi, merepresentasikan kesepakatan umum formal dalam pengartian data

d. Layer Logic, merepresentasikan konsep reasoning terhadap data berharga

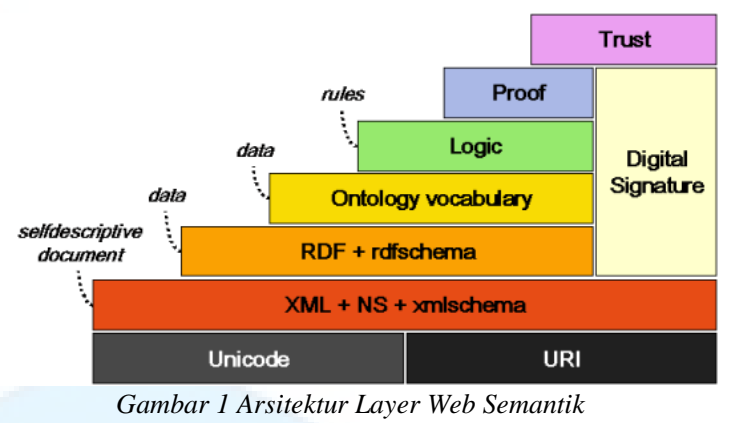

Terdapat tiga teknologi penting yang terlibat dalam penggunaan web semantik yaitu: eXtensible Markup Language (XML), Resource Description Framework (RDF), dan Ontology Web Language (OWL) (Antoniou \& Van Harmelen, 2004).

$\underline{\mathrm{XML}}$

Sebuah XML terdiri dari:

a. Prolog

Prolog terdiri dari sebuah deklarasi XML dan referensi opsional ke dokumen terstruktur eksternal. Contoh deklarasi XML adalah sebagai berikut:

$<$ ?xml version="1.0" encoding="UTF-16"?>

Contoh deklarasi XML tersebut maksudnya bahwa dokumen ini adalah dokumen XML dengan versi 1.0 dan karakter encoding yang digunakan adalah UTF-16

\section{b. Elemen XML}

Elemen XML merepresentasikan sesuatu mengenai apa yang dibahas oleh sebuah dokumen XML seperti elemen buku, pengarang, dan penerbit. Elemen XML merupakan inti dari dokumen XML. Sebuah elemen terdiri dari tag pembuka, konten, dan tag penutup.

Nama tag bisa ditulis apa saja asal memenuhi ketentuan penulisan, yaitu: Karakter pertama harus huruf atau underscore atau colon dan tidak boleh diawali dengan kata "xml" dengan berbagai 
kombinasi besar kecilnya huruf. Isi dari elemen bisa berupa teks, angka, atau elemen lain, atau tidak ada isinya.

Contohnya:

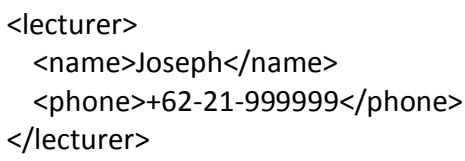

Jika tidak ada isinya, maka elemennya berupa elemen kosong. Contohnya: $<$ lecturer $></$ lecturer $>$

atau bisa ditulis:

$<$ lecturer />

c. Atribut

Elemen kosong tidak berarti tidak berguna, sebab bisa juga terdapat properti yang dianggap sebagai atribut elemen. Atribut adalah pasangan namanilai di dalam tag pembuka.

$<$ lecturer name="Joseph" phone="+62-21999999" / >

Berikut ini adalah contoh XML berupa elemen yang ada nilainya dan ada atributnya:

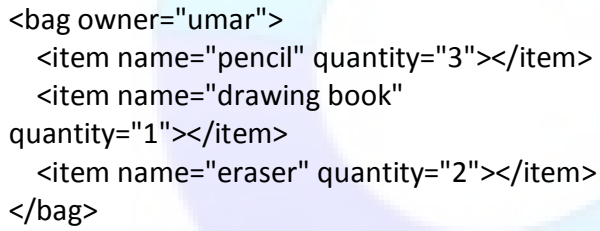

d. Komentar

Komentar adalah potongan teks yang diabaikan oleh mesin saat pembacaan data XML. Formatnya adalah:

$$
<!-- \text { this is a comment --> }
$$

e. Processing Instructions (PIs)

PIs menyediakan mekanisme untuk melewatkan informasi ke sebuah aplikasi bagaimana cara memperlakukan elemen. Format umumnya adalah:

$<$ ?target instruction?>

\section{RDF dan RDF Schema}

Konsep dasar dari RDF adalah resources, properties, dan statements. Misalnya ada pernyataan "Agung is a teacher of Biology Science", bentuk RDF-nya akan menjadi:

$$
\begin{aligned}
& \text { <rdf:Description rdf:about="Biology Science" }> \\
& <\text { rdf:isTaughtBy }>\text { Agung </ rdf:isTaughtBy }> \\
& </ \text { rdf:Description > }
\end{aligned}
$$

Penjelasan mengenai konsep dasar RDF yaitu:

\section{a. Resources}

Resources bisa dikatakan sebagai objek atau sesuatu yang sedang dibahas. Resources bisa berupa orang, tempat, sekolah, rumah, dll. Setiap Resources mempunyai URI (Universal Resource Identifier). URI bisa berupa URL (Universal Resource Locator) atau situs alamat web, atau sejenis identifier unik tertentu. Pada contoh sebelumnya, yang merupakan resources adalah Biology Science.

\section{b. Properties}

Properties adalah resources yang mendeskripsikan hubungan antara resources. Contohnya "written by", "age", "title", dll. Properties juga mempunyai URI asal pendefinisiannya. Pada contoh sebelumnya, yang merupakan properties adalah isTaughtBy.

\section{c. Statements}

Pernyataan adalah pasangan objek-atribut-nilai atau dalam susunan kalimat sama dengan subjekpredikat-objek. Pernyataan berisi resource, property, dan nilai. Nilai bisa berupa resource atau literal. Literal adalah nilai atomik atau nilai yang tidak bisa dipecah lagi.

RDF seperti halnya XML mempunyai struktur yang didefinisikan dalam RDF Schema. RDF Schema adalah kosa kata untuk menjelaskan properties dan classes dari berkas RDF. Hubungan antara RDF dan RDF Schema ditampilkan di Gambar 2.

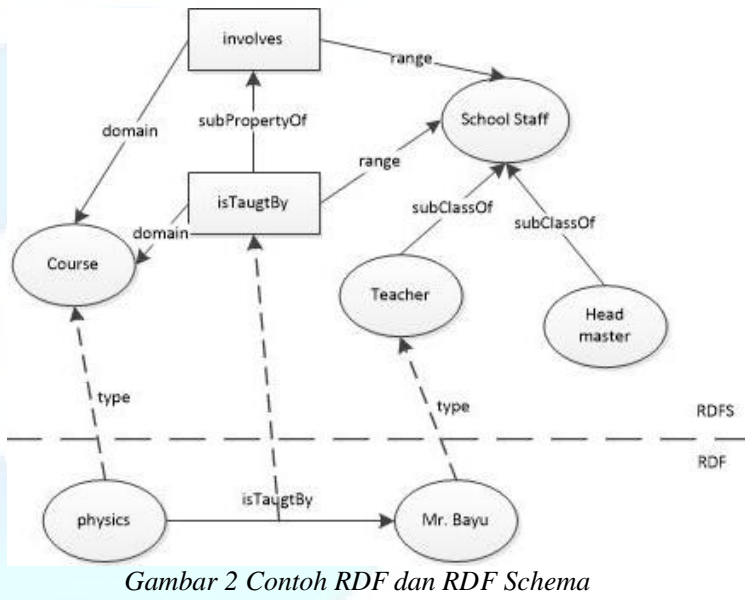

Sintaks RDF Schema yang mengacu pada http://www.w3.org/2000/01/rdf-schema\# dan digunakan di penelitian ini adalah:

- rdfs:Resource, digunakan untuk mendefinisikan Resources.

- rdfs:Class, digunakan untuk mendefinisikan kelas.

- rdfs:Literal, digunakan untuk mendefinisikan nilai atomik atau nilai string.

- rdf:Property, digunakan untuk mendefinisikan properties.

- rdf:Statement, digunakan untuk mendefinisikan pernyataan yang abstrak.

- rdfs:subClassOf, digunakan untuk mendefinisikan hubungan dengan kelas di atasnya. rdfs:domain, digunakan untuk menentukan domain atau bidang dari property yang didefnisikan. 
- rdfs:range, digunakan untuk menentukan batasan dari bidang property yang didefinisikan.

\section{Ontology}

Ontologi merupakan gambaran pengetahuan sebagai susunan konsep dalam sebuah topik tertentu dan menggunakan istilah umum untuk menunjukkan jenis, sifat dan hubungan dari konsep-konsep tersebut (Gruber, 2001). Web Ontology Language atau OWL adalah penerapan ontologi dalam web semantik. OWL berdasarkan pembatasan penggunaan fitur-fiturnya untuk kebutuhan dibedakan menjadi tiga jenis:

\section{a. OWL Full}

OWL Full menggunakan semua fitur OWL tanpa ada batasan dalam penggunaan. Ontologi menggunakan jenis ini akan menjadikan pengetahuan yang digambarkan menjadi lebih lengkap dan kompleks.

\section{b. OWL DL}

OWL DL adalah turunan dari OWL Full dengan keterbatasan pemakaian bahasa OWL. Bahasa ontologi yang dipakai adalah bahasa yang dapat membuat ontologi itu menjadi ontologi yang bersifat efektif dan tidak kompleks.

\section{c. OWL Lite}

OWL Lite lebih membatasi pemakaian bahasa ontologi dibandingkan dengan OWL DL. Hasil dengan jenis ini adalah ontologi yang bersifat efisien karena meminimalkan pemakaian bahasa.

Dalam web semantik, OWL baik Full, DL, maupun Lite tetap menggunakan bahasa RDF/ RDF Schema dengan catatan:

- Penulisan OWL menggunakan sintaks RDF

- Contoh dinyatakan seperti di RDF, menggunakan deskripsi RDF dan informasi penulisannya

- Konstruktor OWL seperti owl:Class, owl:DatatypeProperty, dan owl:ObjectProperty adalah format lain dari komponen RDF seperti rdfs:Class dan rdf:Property

Gambar 3 bisa mewakili tampilan implementasi hubungan substitusi antara RDF/RDF Schema dengan OWL.

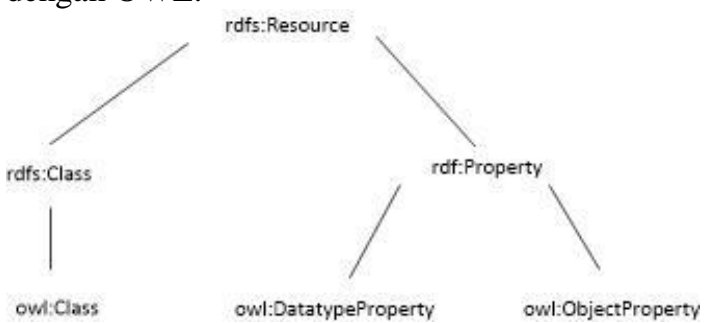

Gambar 3 Hubungan antara RDF/RDF Schema dan OWL $\underline{\text { Triple }}$

Triple adalah unit dasar dari sebuah data RDF. Satu node data tidak akan mempunyai arti, oleh karena itu pernyataan data dalam bentuk triple akan menegaskan suatu arti data tersebut (Vesse, et al., 2009). Sebuah Triple terdiri dari Subjek, Predikat, dan Objek (Price, 2004). Triple bisa ditafsirkan sebagai pernyataan bahwa sebuah subjek terhubung dengan suatu objek yang hubungan tersebut ditentukan oleh sebuah predikat. Contoh penggunaan Triple dalam pemrogramannya dapat dilihat di Gambar 4.

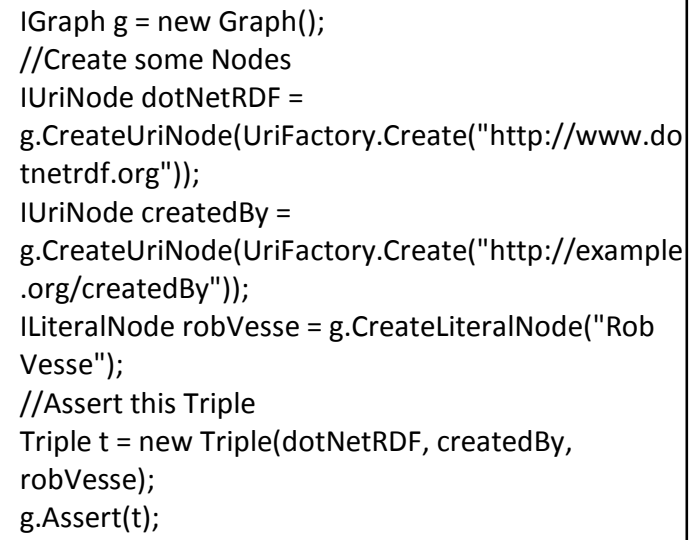

Gambar 4 Kode Penggunaan Triple RDF

\section{METODOLOGI}

Penelitian ini menerapkan tahapan-tahapan System Development Life Cycle (SDLC) dengan model waterfall (Pressman, 2001).

\subsection{Pengumpulan Data}

Tahap pertama yang dilakukan adalah Pengumpulan data. Pengumpulan data dilakukan dengan cara observasi dan studi literatur terhadap ilmu-ilmu yang akan diterapkan seperti web semantik, e-Learning, dll. Tahap ini dilakukan dengan mencari informasi melalui media internet, buku-buku pengetahuan, jurnal-jurnal, dan media lainnya

\subsection{Analisis Kebutuhan Sistem}

Dalam tahap ini, peneliti menganalisis sistem primagamaplus yang akan dipasang fitur web semantik dari segi arsitekturnya yang ditampilkan di Gambar 5 dan fitur-fiturnya. Peneliti juga menganalisis teknologi-teknologi yang digunakan untuk pengembangannya. Pembuatan pembangkit web semantik menggunakan library DotnetRDF (Vesse, et al., 2009). DotnetRDF dipilih karena menggunakan teknologi yang sama dengan aplikasi webnya yaitu teknologi .net framework sehingga memudahkan dalam pengembangan. 


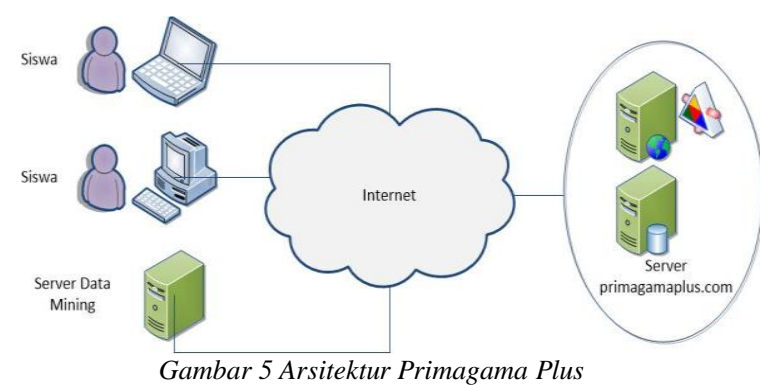

\subsection{Desain Sistem}

Dari diagram use case di Gambar 5, yang ditandai dengan lingkaran merah adalah fitur pembangkit web semantik yang akan dikembankan. Use case fitur pembangkit web semantic itu antara lain:

- Generate Ontology, Administrator membuat file ontologi primagamaplus

- Bulk Create RDF, Administrator membangkitkan file RDF untuk semua materi pembelajaran primagamaplus saat instalasi

- Manage RDF, Sistem membangkitkan file RDF untuk setiap pembuatan, pengubahan, atau penghapusan materi pembelajaran primagamaplus

- Embed RDF, Sistem menampilkan tag RDF di halaman primagamaplus

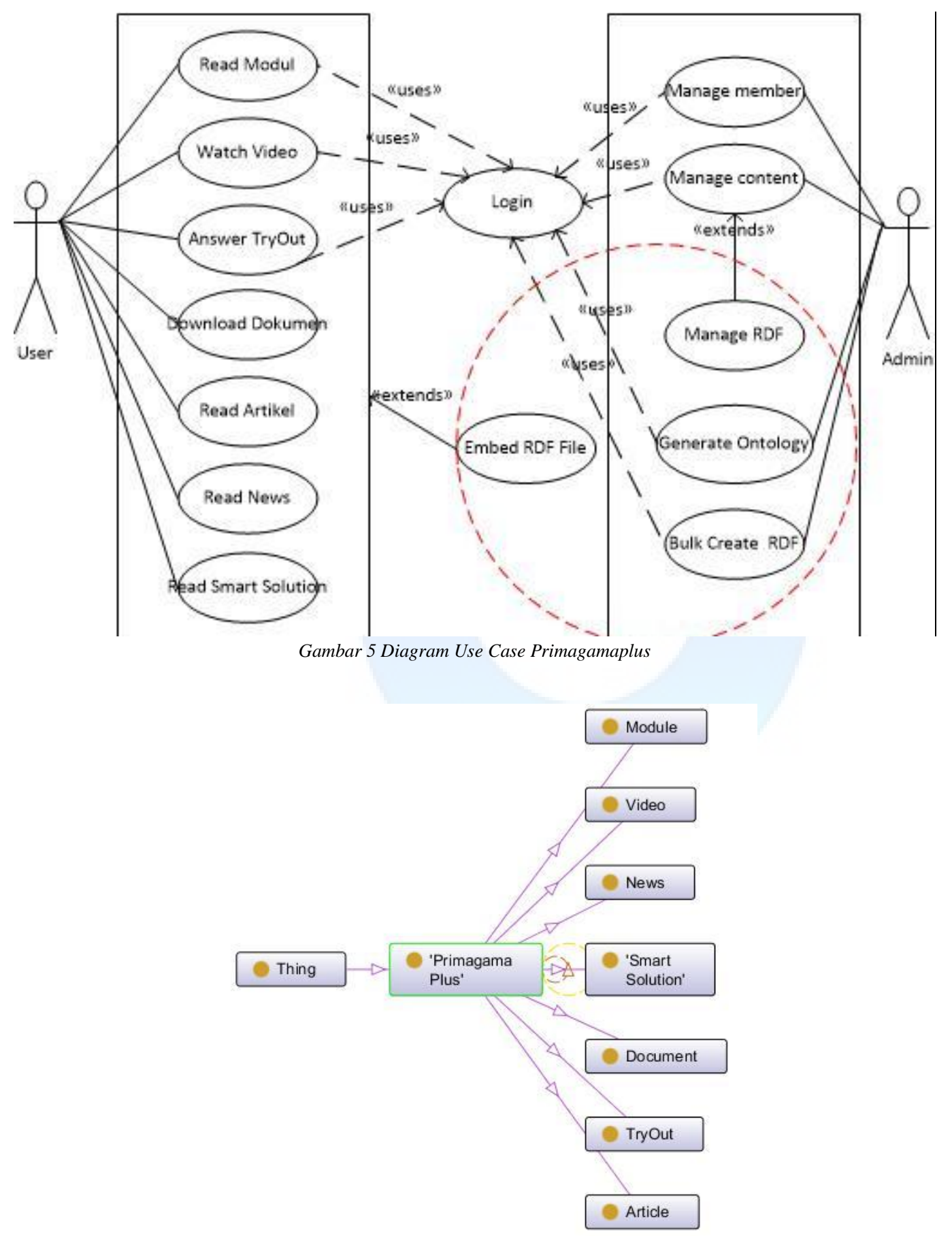

Gambar 6 Skema Ontologi PrimagamaPlus 
Masih di tahap desain sistem, peneliti juga mendesain skema ontologi primagamaplus yang ditampilkan di Gambar 6. Kelas ontologinya pada Gambar 6 terdiri dari kelas PrimagamaPlus, Module, Video, TryOut, Document, Article, News, dan SmartSolution. Properti-properti dari masingmasing kelas dijelaskan di Tabel 1.

Tabel 1 Kelas Ontologi PrimagamaPlus

\begin{tabular}{ll}
\hline \multicolumn{1}{c}{ Kelas } & \multicolumn{1}{c}{ Properti } \\
\hline Primagama & CreatedOn, HasChild, HasTitle, \\
Plus & HasUrl, Rdf:Type \\
& CreatedOn, HasClassLevel, \\
& HasFieldOfStudy, HasParent, \\
Video & HasTitle, HasUrl, Rdf:Type \\
& CreatedOn, HasClassLevel, \\
& HasFieldOfStudy, HasParent, \\
& HasTitle, HasUrl, Rdf:Type \\
TryOut & HasClassLevel, \\
& HasFieldOfStudy, HasParent, \\
& HasTitle, HasUrl, Rdf:Type \\
Document & CreatedOn, HasParent, HasTitle, \\
& HasUrl, Rdf:Type \\
News & CreatedOn, HasContent, \\
& HasParent, HasTitle, HasUrl, \\
& Rdf:Type \\
Article & CreatedOn, HasContent, \\
& HasParent, HasTitle, HasUrl, \\
& Rdf:Type \\
Smart & CreatedOn, HasClassLevel, \\
Solution & HasFieldOfStudy, HasParent, \\
& HasTitle, HasUrl, Rdf:Type \\
\hline
\end{tabular}

\subsection{Pembuatan Program}

Kode pembuatan primagamaplus dinamakan Aquera3. Dalam Pembuatan, projek baru ditambahkan di solusi Aquera3 dengan nama AqueraSemantic. setiap kode program yang akan dibuat dalam penelitian ini akan diletakkan di projek tersebut. Bahasa pemrograman yang digunakan adalah ASP.NET dan C\#.NET. Library untuk pembangkitan web semantik dan ontologi menggunakan DotnetRDF. Contoh listing pembangkitan RDF dapat dilihat di gambar 4.

\subsection{Uji dan Analisis Hasil Program}

Aplikasi AqueraSemantic yang telah dibuat programnya dilakukan pengujian untuk mencari kesalahan kode atau logika. Pengujian ini menggunakan black-box testing (Pressman, 2001). Hasil dari pembangkitan juga diuji kevalidan datanya. Pengujian berkas RDF hasil pembangkitan menggunakan program pembaca berkas RDF yang ditampilkan menjadi tabel Triple RDF.

\section{HASIL dan PEMBAHASAN}

Tahapan SDLC setelah desain sistem dan pembuatan program adalah Uji coba dan Analisis hasil program. Pada tahap ini setiap program yang dibuat diuji dari sisi integritasnya dengan PrimagamaPlus, efisiensi, dan performanya.

\subsection{Pengujian Pembuatan Ontologi}

Pembuatan Ontologi dilakukan oleh administrator. Tampilan halamannya dapat dilihat di Gambar 7. Aksi yang dilakukan oleh administrator hanyalah menekan tombol "Ontology" di halaman tersebut. Kemudian, aplikasi akan mengeksekusi metode OntologyButton_Click yang berisi kode untuk membuat file ontologi yang berisi deklarasi kelas, object property, dan datatype property. Object property adalah properti dari kelas yang dideklarasikan di file ontologi yang berupa objek. Datatype property adalah properti dari kelas di file ontologi juga yang berupa data string dengan format tertentu. Daftar object property serta datatype property dapat dilihat di Tabel 2.

Tabel 2 Daftar Object dan Datatype Property

\begin{tabular}{|c|c|c|c|}
\hline $\begin{array}{c}\text { Nama } \\
\text { Properti }\end{array}$ & \multicolumn{2}{|c|}{ Range } & Jenis \\
\hline hasParent & \multicolumn{2}{|c|}{ PrimagamaPlus } & Object Property \\
\hline hasChild & \multicolumn{2}{|c|}{ PrimagamaPlus } & Object Property \\
\hline hasTitle & \multicolumn{2}{|l|}{ String } & Datatype Property \\
\hline hasContent & \multicolumn{2}{|l|}{ String } & Datatype Propert \\
\hline createdOn & \multicolumn{2}{|l|}{ Datetime } & Datatype Property \\
\hline hasUrl & \multicolumn{2}{|l|}{ anyUri } & Datatype Property \\
\hline hasClassLevel & \multicolumn{2}{|l|}{ String } & Datatype Property \\
\hline hasFieldOfStud & \multicolumn{2}{|l|}{ String } & Datatype Property \\
\hline hasDescription & \multicolumn{2}{|l|}{ String } & Datatype Property \\
\hline \multicolumn{4}{|l|}{ RDF Generator } \\
\hline \multicolumn{4}{|c|}{ Ontology generator } \\
\hline \multicolumn{4}{|l|}{ Ontology } \\
\hline \multicolumn{4}{|l|}{ Bulk Create RDF } \\
\hline Primagama Plus & Article & News & Smat Solution \\
\hline Modul & Video & Documer & Tryout \\
\hline
\end{tabular}

File ontologi yang telah dibuat disimpan di server web dengan lokasi “ |rdflontology.rdf”. Potongan deklarasi object property serta datatype property dari file ontologi dapat dilihat di gambar 9 .

\subsection{Pengujian Bulk Create RDF dan Manage RDF}

Bulk Create atau pembangkitan file RDF untuk keseluruhan materi pembelajaran PrimagamaPlus dilakukan oleh Administrator sekali saat instalasi Pembangkit RDF ini. Untuk seterusnya, sistemlah yang bekerja melalui fitur manajemen RDF untuk membuat, mengupdate, atau menghapus 
file RDF sesuai dengan perlakuan terhadap materi pembelajaran PrimagamaPlus. Halaman untuk pembangkitan awal sama dengan halaman pembangkit ontologi dan ditampilkan di Gambar 8. Contoh cuplikan kode pembuatan file RDF materi Smart Solution dapat dilhat di gambar 10. Kode pembuatan file RDF kelas lainnya menyesuaikan dengan properti dan sifat materi masing-masing. Setiap file RDF yang dihasilkan akan disimpan di harddisk server yang daftarnya dapat dilihat di Tabel 3.

Tabel 3 Daftar Lokasi File RDF

\begin{tabular}{|c|c|}
\hline Kelas & Lokasi file yang dibuat \\
\hline \multirow{8}{*}{$\begin{array}{l}\text { PrimagamaPlu } \\
s\end{array}$} & $\sim$ |rdflprimagamaplus.rdf \\
\hline & $\sim$ rdf $\backslash$ module.rdf \\
\hline & $\sim$ rdflvideo.rdf \\
\hline & $\sim \mid$ rdfltryout.rdf \\
\hline & $\sim$ rdfldocument.rdf \\
\hline & $\sim$ rdflnews.rdf \\
\hline & $\sim$ rdflarticle.rdf \\
\hline & $\sim$ |rdflsmartsolution.rdf \\
\hline Module & |rdflmodulel"module_id".rdf \\
\hline Video & |rdflvideol"video_id".rdf \\
\hline TryOut & |rdfltryout|"tryout_id".rdf \\
\hline Document & |rdfldocument $\mid$ "document_id".rdf \\
\hline News & |rdflnews〉|"news_id".rdf \\
\hline Article & $\sim$ rdflarticlel"article_id".rdf \\
\hline Smartsolution & $\begin{array}{l}\text { \rdf|smartsolution } \backslash \bar{s} \text { smartsolution } \\
\text { id".rdf }\end{array}$ \\
\hline
\end{tabular}

<owl:ObjectProperty

rdf:about="http://localhost:1500/rdf/ontology.rdf\#hasC hild">

$<$ rdfs:domain

rdf:resource="http://localhost:1500/rdf/ontology.rdf\#Pr imagamaPlus" />

$<$ rdfs:range

rdf:resource="http://localhost:1500/rdf/ontology.rdf\#Pr

imagamaPlus" />

$<$ owl:ObjectProperty>

<owl:DatatypeProperty

rdf:about="http://localhost:1500/rdf/ontology.rdf\#hasC

lassLevel">

$<$ rdfs:domain

rdf:resource="http://localhost:1500/rdf/ontology.rdf\#Pr imagamaPlus" />

$<$ rdfs:range rdf:resource="\&xsd;string" />

$<$ /owl:DatatypeProperty>

$<$ <owl:DatatypeProperty

rdf:about="http://localhost:1500/rdf/ontology.rdf\#hasC ontent">

$<$ rdfs:domain

rdf:resource="http://localhost:1500/rdf/ontology.rdf\#Pr

imagamaPlus" />

$<$ rdfs:range rdf:resource="\&xsd;string" />

$</$ owl:DatatvpePropertv>

Gambar 9 Cuplikan File Ontologi

\subsection{Pengujian Penyisipan RDF ke Halaman PrimagamaPlus}

Setiap pengguna mengakses halaman PrimagamaPlus, aplikasi mengeksekusi metode penampil RDF untuk menampilkan file RDF yang telah disimpan. Metode ini dipasang di template utama Primagamaplus agar mencakup semua halaman PrimagamaPlus. Kerja metode tersebut adalah mengetahui jenis dan identitas halaman yang sedang diakses, kemudian memberi keluaran berupa tag html yang berisi link RDF yang sesuai. Hasilnya adalah tag links html yang berisi url file RDF sesuai dengan halaman yang diakses. Contoh hasilnya dapat dilihat di gambar 10.

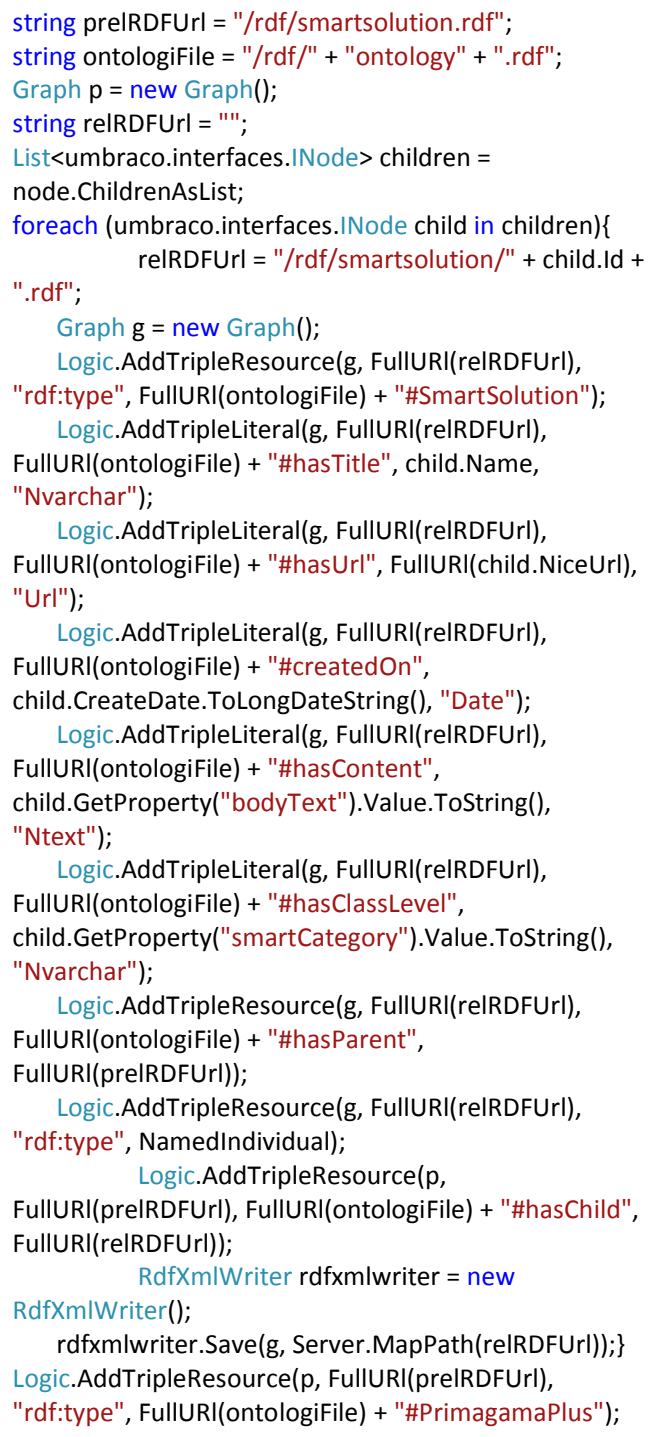

Gambar 10 Cuplikan Kode Pembuatan RDF Smart Solution

$<$ link type="application/rdf+xml" rel="alternate" href="http://primagamaplus.com/rdf/article/1266.x $\mathrm{ml} />$

Gambar 11 Cuplikan Tag link HTML penampil data RDF 


\subsection{Pengujian Berkas RDF Hasil Pembangkitan}

Pengujian berkas-berkas RDF dilakukan dengan mengakses berkas RDF menggunakan aplikasi pembaca web semantik kemudian divalidasi struktur datanya. Listing 5 menampilkan data rdf di halaman http://primagamaplus.com. Berkas tersebut diambil datanya menggunakan validator RDF sederhana menghasilkan tabel triple dengan kolom subyek, predikat, dan obyek dan datanya berupa konten berkas RDF. Hasil validator RDF dapat dilihat di Gambar 13.

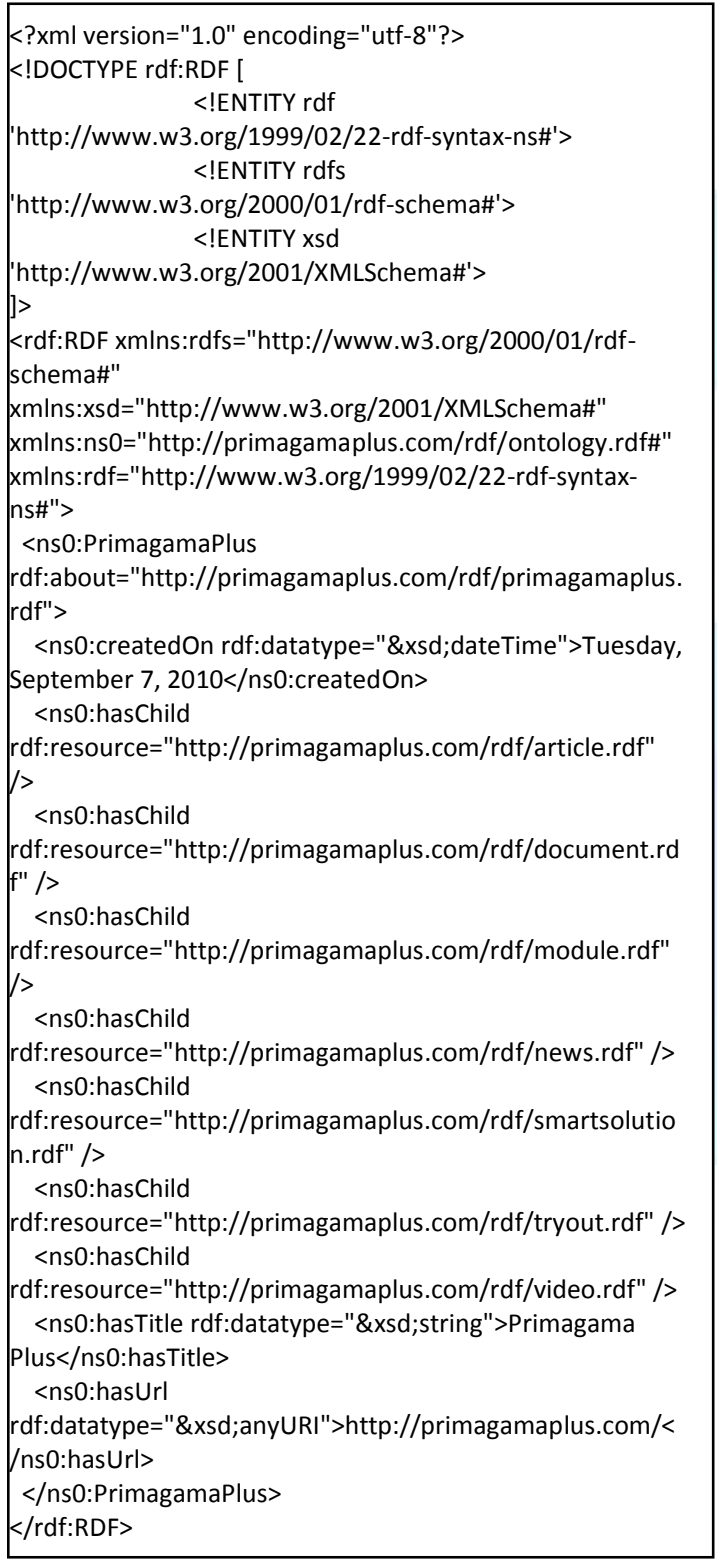

Gambar 12 Berkas RDF halaman beranda PriamagamaPlus

\section{SIMPULAN dan SARAN}

Kesimpulan yang dapat diambil dalam penelitian ini adalah:

Pembangkit data web semantik RDF/XML menggunakan library DotnetRDF telah berhasil dirancang.

a. Pembangkit data web semantik RDF/XML menggunakan library DotnetRDF telah berhasil dirancang.

b. Pembangkit ontologi yang dihasilkan telah disesuaikan dengan fitur konten eLearning PrimagamaPlus, yaitu modul, video, tryout, berita, artikel, smart solution, dan dokumen akademik.

c. Pengelolaan web semantik bersifat otomatis, yaitu setiap konten yang ditambahkan, diubah, atau dihapus maka file RDF untuk konten tersebut akan mengalami perlakuan serupa.

d. Berkas RDF hasil pembangkitan telah sesuai dengan konsep Triple RDF karena telah teruji dengan validator RDF.

\section{DAFTAR RUJUKAN}

Antoniou, G. \& Van Harmelen, F., 2004. A Semantic Web Primer. In: Massachusetts, London, England: MIT Press Cambridge, pp. 44-171.

Berners-Lee, T., Hendler, J. \& Lassila, O., 2001. The Semantic Web. Scientific American.

Berriman, F. et al., 2005. Microformats Web. [Online] Available at: http://microformats.org/ [Accessed 14 October 2014].

Bikakis, N. et al., 2013. The XML and Semantic Web Worlds: Technologies, Interoperability and Integration. A survey of the State of the Art. p. 4.

Facebook, 2007. Open Graph Protocol. [Online] Available at: http://ogp.me [Accessed 14 October 2014].

Gruber, T., 2001. What is an Ontology?. Stanford University.

Jenkins, M. \& Hanson, J., 2003. E-Learning Series. LTSN Generic Centre: s.n.

Microsoft Developer Netwrok, n.d. Structured Query Language (SQL). [Online]

Available at: http://msdn.microsoft.com/en$\mathrm{gb} /$ library/windows/desktop/ms714670(v= vs.85).aspx [Accessed 511 2014].

Miller, E. \& Koivunen, M.-R., 2001. W3C Semantic Web Activity. [Online] Available at: http://www.w3.org/2001/12/semweb-fin/w3csw 
Jurnal Sistem Informasi, Volume 5, Nomor 3, Maret 2015, 200-208

rimagamaplus.com/rdf/primagamaplus.rdf Tampil RDF

\begin{tabular}{|c|c|c|}
\hline subyek & predikat & obyek \\
\hline $\begin{array}{l}\text { http://primagamaplus.com } \\
\text { /rdf/primagamaplus.rdf }\end{array}$ & $\begin{array}{c}\text { http://www.w3.0ra/1999/02/22-rdf-syntax- } \\
\text { ns \#type } \\
\end{array}$ & http://primaqamaplus.com/rdf/ontology.rdf\#Primaqami \\
\hline $\begin{array}{l}\text { http://primagamaplus.com } \\
\text { /rdf/primagamaplus.rdf }\end{array}$ & $\begin{array}{l}\text { http://primagamaplus.com } \\
\text { irdf/ontology,rdf\#createdon }\end{array}$ & $\begin{array}{c}\text { Tuesday, September 7, 2010^^http://www.w3.or! } \\
\text { /2001/XMLSchema\#dateTime }\end{array}$ \\
\hline $\begin{array}{l}\text { http://primagamaplus.com } \\
\text { /rdf/primagamaplus.rdf }\end{array}$ & $\begin{array}{l}\text { http://primagamaplus.com } \\
\text { Lrdf/ontology.rdf\#hasChild }\end{array}$ & $\underline{\text { http://primagamaplus.com/rdf/article.rdf }}$ \\
\hline $\begin{array}{l}\text { http://primagamaplus.com } \\
\text { /rdf/primagamaplus.rdf }\end{array}$ & $\begin{array}{l}\text { http://primagamaplus.com } \\
\text { Lrdf/ontology.rdf\#hasChild } \\
\end{array}$ & $\underline{\text { http://primaqamaplus.com/rdf/document.rdf }}$ \\
\hline $\begin{array}{l}\text { http://primagamaplus.com } \\
\text { /rdf/primagamaplus.rdf }\end{array}$ & $\begin{array}{l}\text { http://primagamaplus.com } \\
\text { Lrdf/ontology.rdf\# \#asChild }\end{array}$ & http://primaqamaplus.com/rdf/module.rdf \\
\hline $\begin{array}{l}\text { http://primagamaplus.com } \\
\text { /rdf/primagamaplus.rdf }\end{array}$ & $\begin{array}{l}\text { http://primagamaplus.com } \\
\text { Lrdf/ontology.rdf\#hasChild }\end{array}$ & $\underline{\text { http://primaqamaplus.com/rdf/news.rdf }}$ \\
\hline $\begin{array}{l}\text { http://primagamaplus.com } \\
\text { /rdf/primagamaplus.rdf }\end{array}$ & $\begin{array}{l}\text { http://primagamaplus.com } \\
\text { Lrdf/ontology.rdf\#hasChild }\end{array}$ & http://primaqamaplus.com/rdf/smartsolution.rdf \\
\hline $\begin{array}{l}\text { http://primagamaplus.com } \\
\text { /rdf/primagamaplus.rdf }\end{array}$ & $\begin{array}{l}\text { http://primagamaplus.com } \\
\text { Lrdf/ontology.rdf\#hasChild } \\
\end{array}$ & http://primagamaplus.com/rdf/tryout.rdf \\
\hline $\begin{array}{l}\text { http://primagamaplus.com } \\
\text { /rdf/primagamaplus.rdf }\end{array}$ & $\begin{array}{l}\text { http://primagamaplus.com } \\
\text { Lrdf/ontology.rdf\#hasChild }\end{array}$ & http://primaqamaplus.com/rdf/video.rdf \\
\hline $\begin{array}{l}\text { http://primagamaplus.com } \\
\text { /rdf/primagamaplus.rdf }\end{array}$ & $\begin{array}{l}\text { http://primagamaplus.com } \\
\text { Lrdf/ontology,rdf\#hasTitle } \\
\end{array}$ & $\begin{array}{l}\text { Primagama Plus^^http://www.w3.org } \\
\text { /2001/XMLSchema\#string }\end{array}$ \\
\hline $\begin{array}{l}\text { http://primagamaplus.com } \\
\text { /rdf/primagamaplus.rdf }\end{array}$ & $\begin{array}{l}\text { http://primagamaplus.com } \\
\text { /rdf/ontology.rdf\#hasUrl }\end{array}$ & $\begin{array}{c}\text { http://primagamaplus.com/^^^http://www.w3.org } \\
\text { /2001/XMLSchema\#anyURI }\end{array}$ \\
\hline
\end{tabular}

Gambar 13 Tampilan Berkas RDF dalam bentuk Tabel

O'Reilly, T., 2005. What is Web 2.0 Design Patterns and Business Models for the Next Generation of Software. [Online] Available at: http://oreilly.com/web2/archive/what-is-web-20.html

PgPlus Team, 2010. PrimagamaPlus. [Online] Available at: http://primagamaplus.com

Pressman, R. S., 2001. Black-box Testing. In: Software Engineering A Practitioner's Approach Fifth Edition. s.l.:McGraw-Hill, pp. 459-468.

Pressman, R. S., 2001. The Linear Sequential Model. In: Software Engineering A Practitioner's Approach Fifth Edition. s.1.:McGraw-Hill, pp. 28-30.
Price, R., 2004. What Is An RDF Triple?. [Online] Available at: http://www.robertprice.co.uk/robblog/2004 /10/what_is_an_rdf_triple_-shtml/

Tran, K., n.d. Semantic Web Mining.

Vesse, R. et al., 2009. dotNetRDF - Working with Triple Stores. [Online] Available at: https://bitbucket.org/dotnetrdf/dotnetrdf/wi ki/UserGuide/Working\%20with\%20Triple $\%$ 20Stores

Vesse, R. et al., 2009. dotNetRDF - Semantic Web, RDF and SPARQL Library for C\#/.Net. [Online] Available at: http://www.dotnetrdf.org/ 